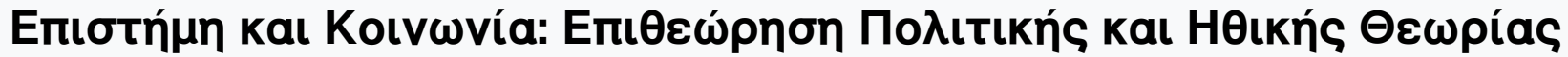

Tó 15 (2005)

\section{$\triangle$ เapӨopá}

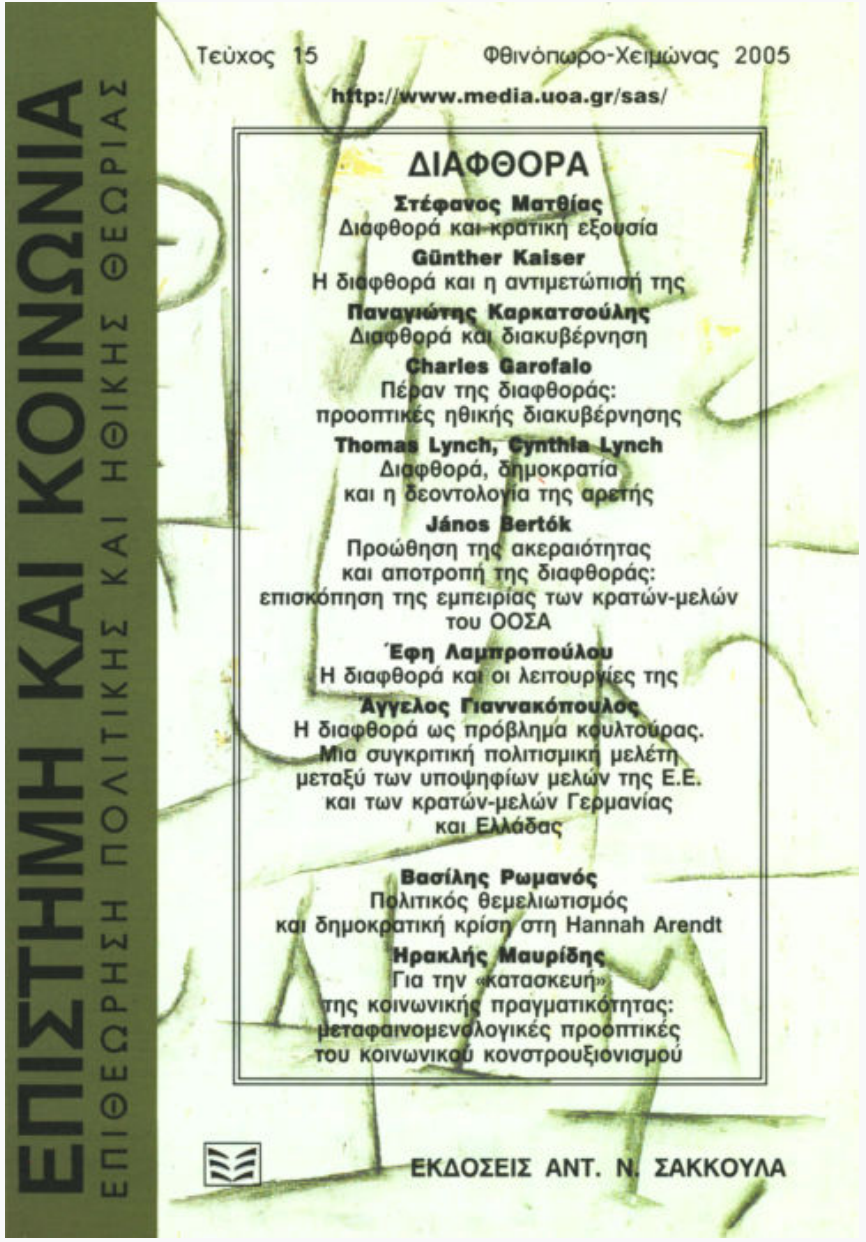

Anthony Giddens, H $\mu \varepsilon \tau a \mu o ́ p \varphi \omega \sigma \eta$ tns

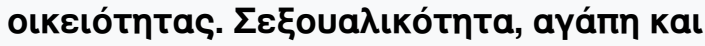

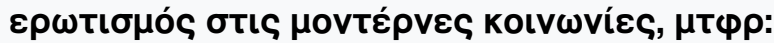

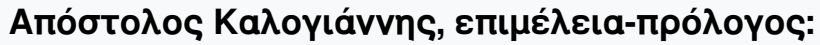
Mretíva Ntáßou

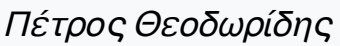

doi: $10.12681 /$ sas.604

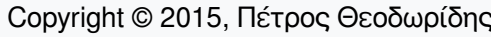

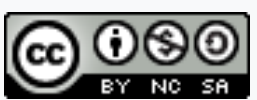

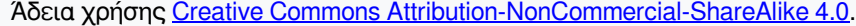

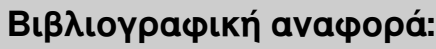

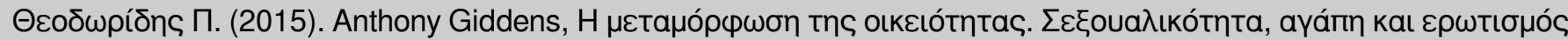

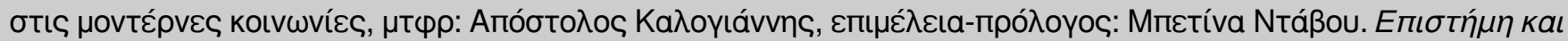

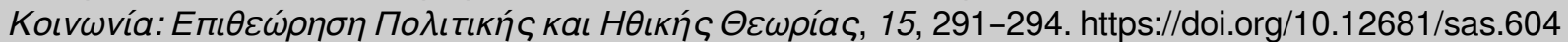




\section{BIBAIOIAPOYЕIAEEIL}

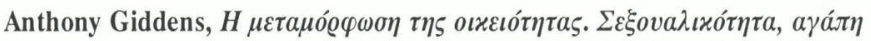

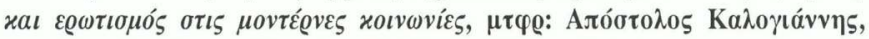

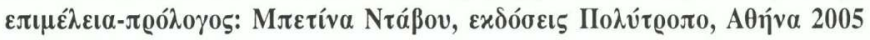

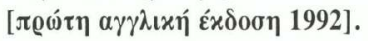

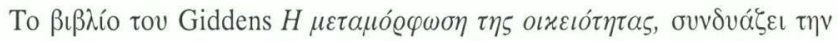

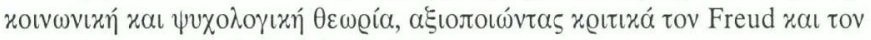

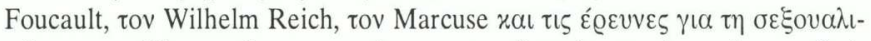

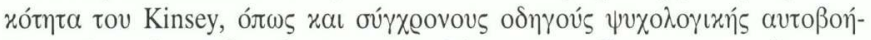

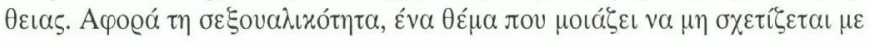

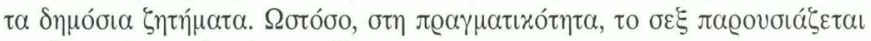

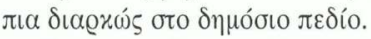

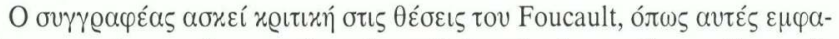

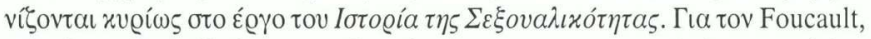

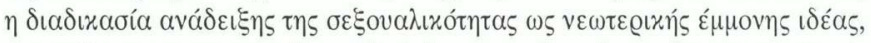

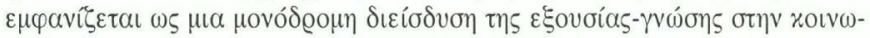

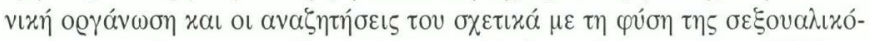

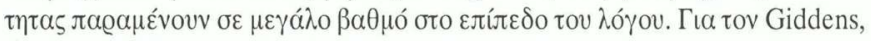

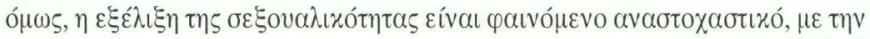

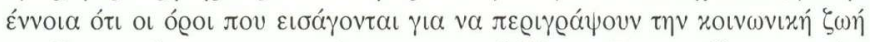

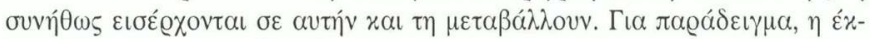

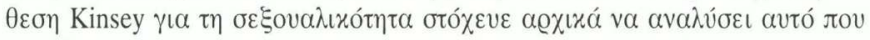

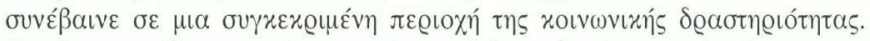

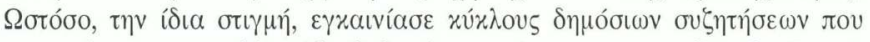

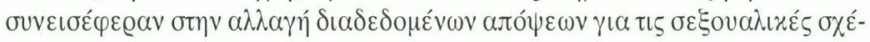

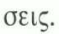

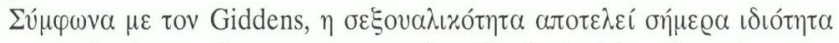

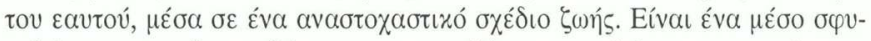

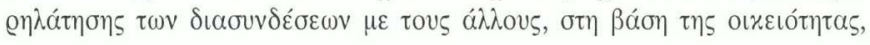




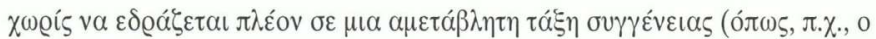

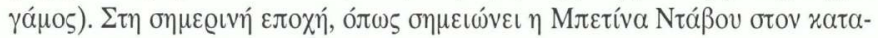

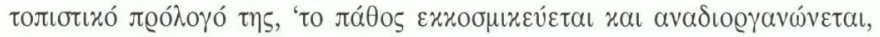

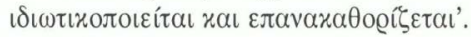

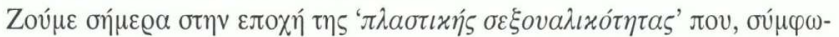

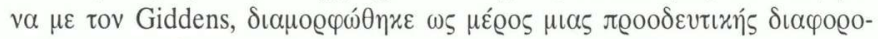

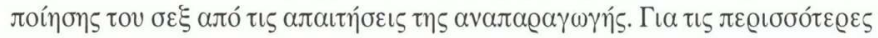

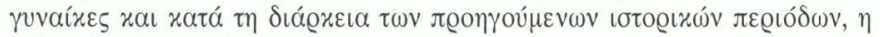

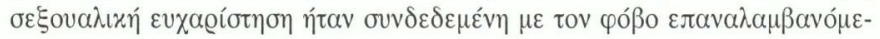

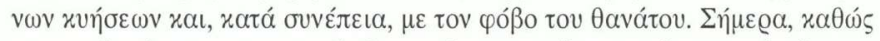

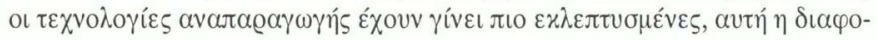

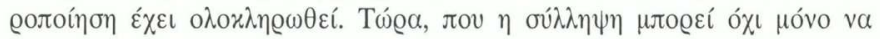

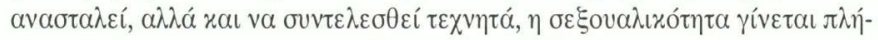

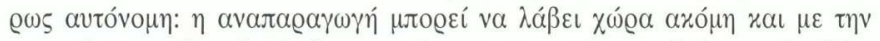

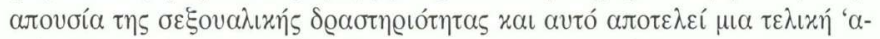

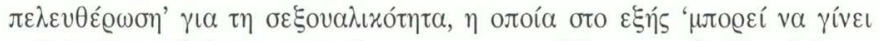

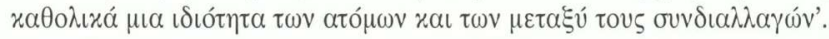

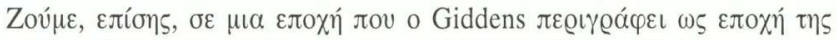
‘a

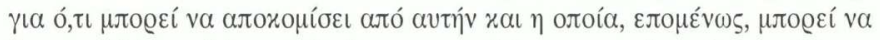

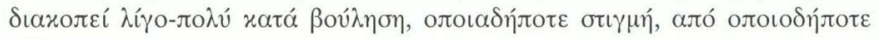

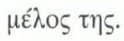

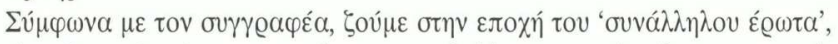

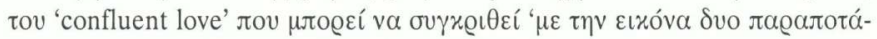

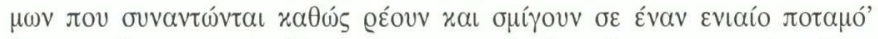

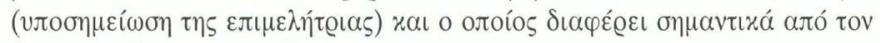

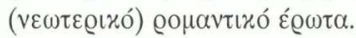

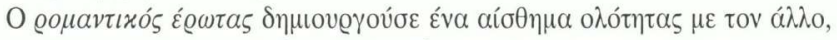

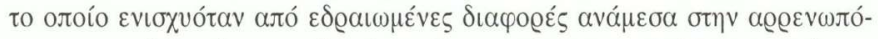

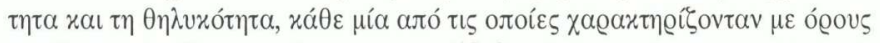

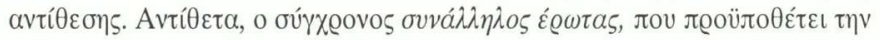

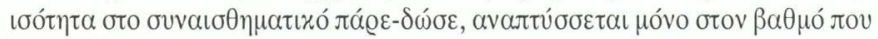

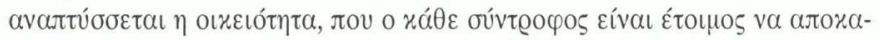

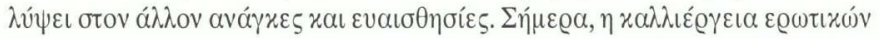

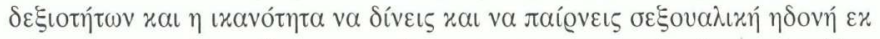

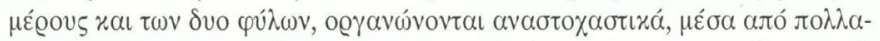

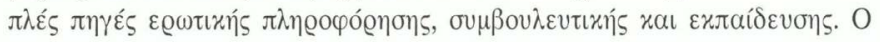




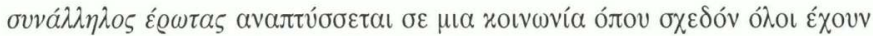

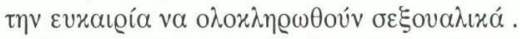

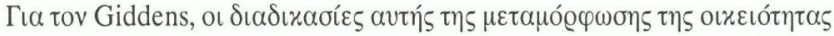

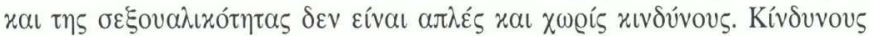

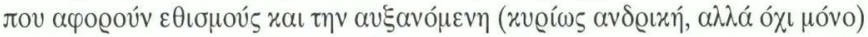

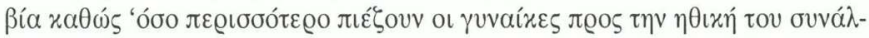

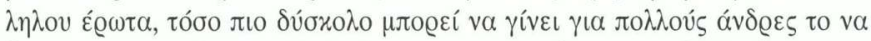

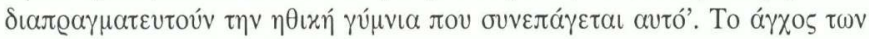

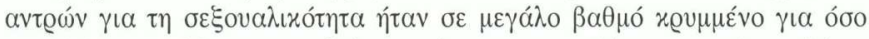

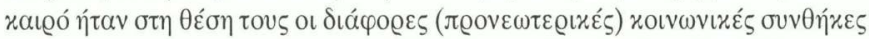

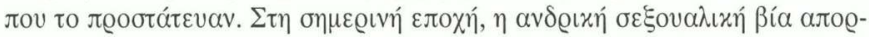

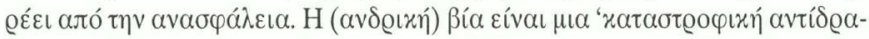

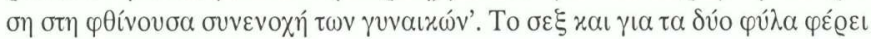

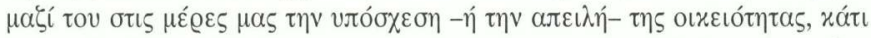

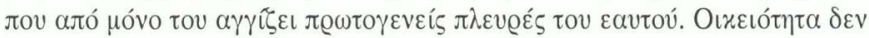

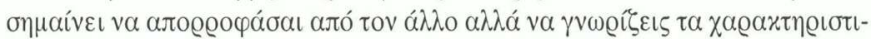

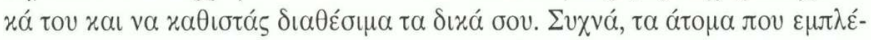

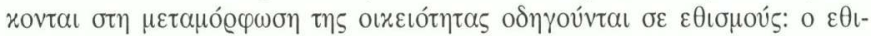

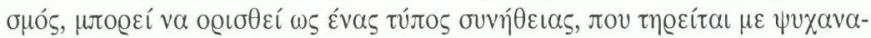

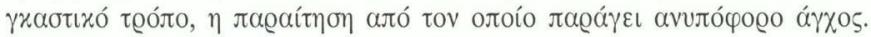

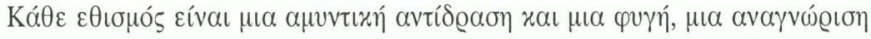

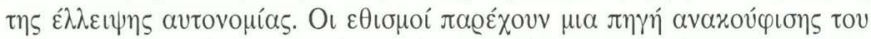

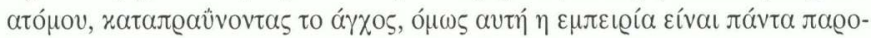

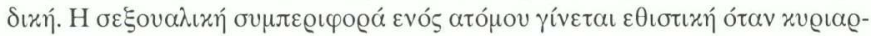

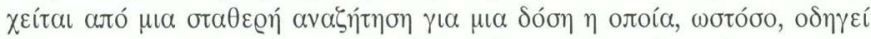

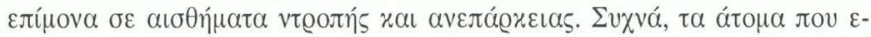

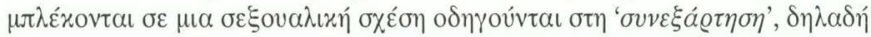

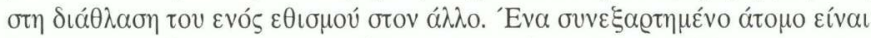

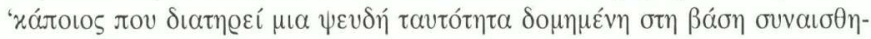

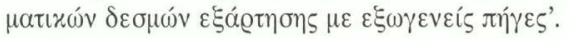

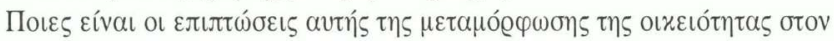

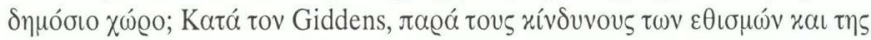

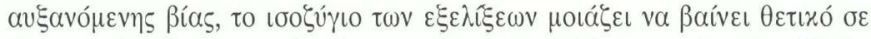

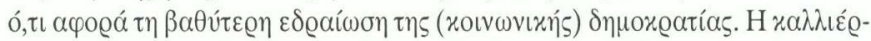

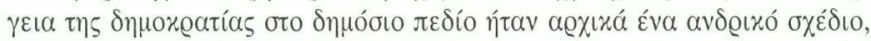

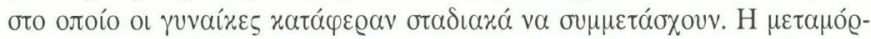

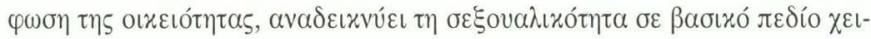




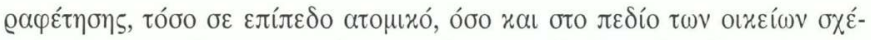

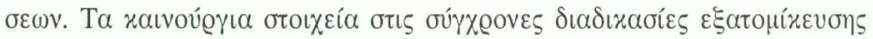

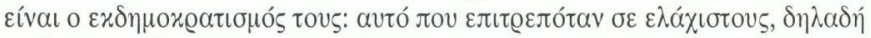

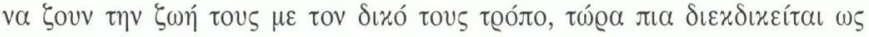

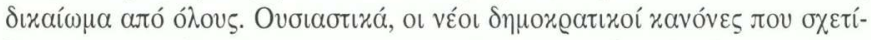

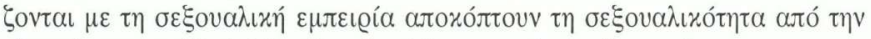

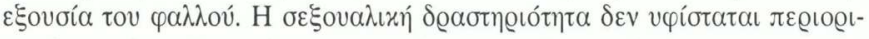

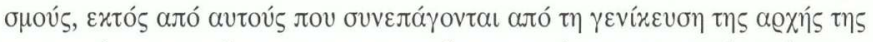

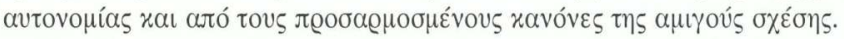

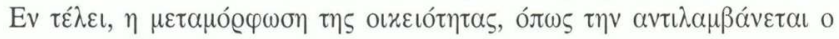

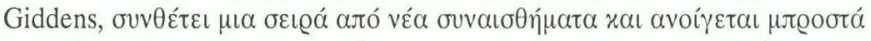

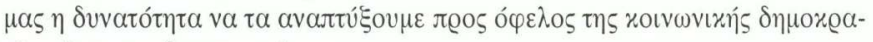

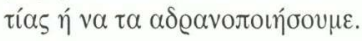

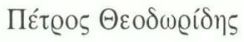

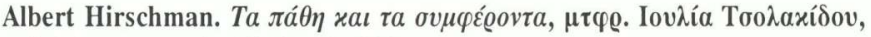

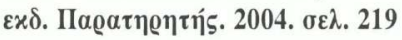

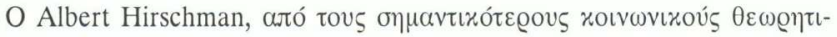

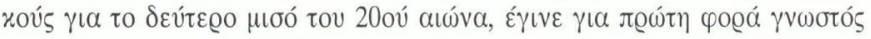

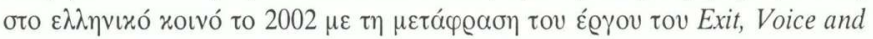

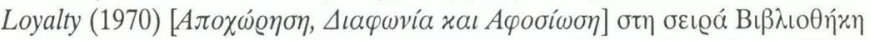

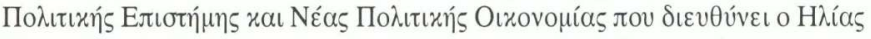

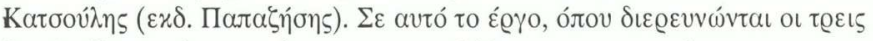

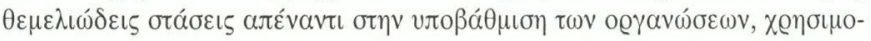

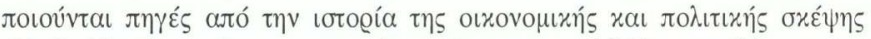

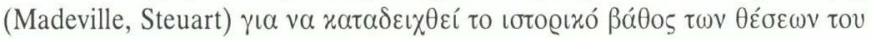

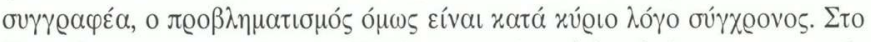

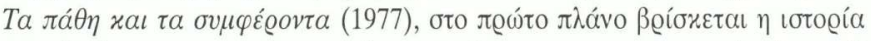

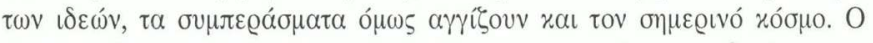

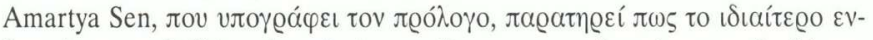

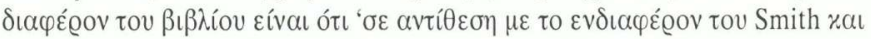

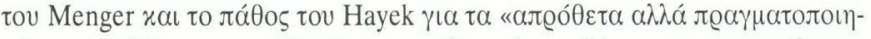

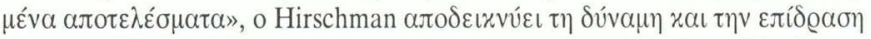

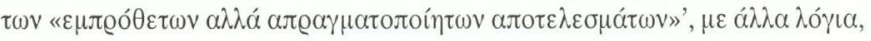

